\title{
RECORDING INFORMATION ON ARCHITECTURAL HERITAGE SHOULD MEET THE REQUIREMENTS FOR CONSERVATION Digital Recording Practices at the Summer Palace
}

\author{
Long Zhang ${ }^{\mathrm{a} *}$, Yipeng Cong ${ }^{\mathrm{b}}$, Cong $\mathrm{Wu}^{\mathrm{a}}$, Chengjun $\mathrm{Bai}^{\mathrm{c}}$, Chen $\mathrm{Wu}^{\mathrm{d}}$ \\ a School of Architecture, Tianjin University, Tianjin 300072, China - arcdragon@163.com, wu.cong@hotmail.com \\ b Administrative office of the Summer Palace, Beijing 100091, China, - congyipeng@sina.com \\ c School of Civil Engineering, Tianjin University, Tianjin 300072, China - babybcj@sina.com \\ d Tianjin Chengjian University, Tianjin 300384, China -chen_w_2012@tcu.edu.cn
}

\section{Commission VI, WG VI/4}

KEY WORDS: Heritage Conservation, Handle Measurement, 3D Laser Scanning, BIM

\begin{abstract}
:
The recording of Architectural heritage information is the foundation of research, conservation, management, and the display of architectural heritage. In other words, the recording of architectural heritage information supports heritage research, conservation, management and architectural heritage display. What information do we record and collect and what technology do we use for information recording? How do we determine the level of accuracy required when recording architectural information? What method do we use for information recording? These questions should be addressed in relation to the nature of the particular heritage site and the specific conditions for the conservation work.
\end{abstract}

In recent years, with the rapid development of information acquisition technology such as Close Range Photogrammetry, 3D Laser Scanning as well as high speed and high precision Aerial Photogrammetry, many Chinese universities, research institutes and heritage management bureaux have purchased considerable equipment for information recording. However, the lack of understanding of both the nature of architectural heritage and the purpose for which the information is being collected has led to several problems. For example: some institutions when recording architectural heritage information aim solely at high accuracy. Some consider that advanced measuring methods must automatically replace traditional measuring methods. Information collection becomes the purpose, rather than the means, of architectural heritage conservation.

Addressing these issues, this paper briefly reviews the history of architectural heritage information recording at the Summer Palace (Yihe Yuan, first built in 1750), Beijing. Using the recording practices at the Summer Palace during the past ten years as examples, we illustrate our achievements and lessons in recording architectural heritage information with regard to the following aspects: (buildings') ideal status desired, (buildings') current status, structural distortion analysis, display, statue restoration and thematic research. Three points will be highlighted in our discussion:

1. Understanding of the heritage is more important than the particular technology used:

Architectural heritage information collection and recording are based on an understanding of the value and nature of the architectural heritage. Understanding is the purpose, whereas information collection and recording are the means.

2. Demand determines technology:

Collecting and recording architectural heritage information is to serve the needs of heritage research, conservation, management and display. These different needs determine the different technologies that we use.

3. Set the level of accuracy appropriately:

For information recording, high accuracy is not the key criterion; rather an appropriate level of accuracy is key. There is considerable deviation between the nominal accuracy of any instrument and the accuracy of any particular measurement.

\section{SUMMARY}

Architectural heritage information can be divided into building information and environmental information. Building information generally consists of spatial, physical (material) and historical information. This paper mainly discusses spatial information. The Summer Palace (Qingyi Yuan 清渏园) was founded in 1750 and burned by the British and French allied forces in 1860. Restored in 1886 and renamed as Yihe Yuan 䝠 和园, the Summer Palace has survived till today and was listed as UNESCO World Cultural Heritage in 1998.

Since 2004, Institute of Architectural History and Theory at the School of Architecture, Tianjin University has participated in the research and conservation of the Summer Palace carried out a number of activities such as organising historical archives,

* Corresponding author 
recording heritage information, making conservation plans and engineering designs, as well as heritage display. In the process of recording architecture heritage information, we used all the methods of spatial information acquisition (Fig.1), except for satellite remote sensing. We have now come to the understanding that recording heritage information is the most important part of heritage conservation. However, the employment of the technical means and ways of recording information collection must be determined by the needs of heritage conservation.

\section{HISTORY OF INFORMATION RECORDING AT THE SUMMER PALACE}

\subsection{Historical Records of the Summer Palace in the Qing Dynasty (1750-1912)}

The information record of ancient Chinese garden architecture are diversified because of the different purposes. Chinese traditional Boundary Drawings are used to record architectural scene faithfully. Traditional landscape paintings and poems are used to describe the artistic conception of a garden. Characters are used to describe the origin of construction, spatial relation, function and activity of garden,such as garden notes, travel notes and poems. Two dimensional drawings and text are used to record the status of garden architecture in preparation for maintenance. The existing historical records of the Summer Palace can be roughly divided into the following three categories:

\subsubsection{Paintings}

Qingyi Yuan Section of Wanshou qingdian tu (Painting of Birthday Celebration for the Chongqing Empress in the Qingyi Yuan ) (Fig.2) is on the background of front mountain and front lake.It describes the birthday celebration Emperor Qianlong held for his mother.The architectures on it are highly realistic. But the theme of the picture is to record celebration, architectures are background.So some architectures are omitted or simplified according to the needs of picture.It's not completely faithful to the actual situation of Qingyi Yuan.

\subsubsection{Literature}

Literature is the main method to record Qingyi Yuan in Qing Dynasty. There were garden notes(such as Notes of Longevity Hill and Kunming Lake and Notes of Da Bao En Yan Shou Temple)and more than 1500 poems written by Emperor Qianlong which expressed his motivation, aesthetics and activities of the garden.The document which recorded the architectural space orientation and interior space of Qingyi Yuan are Ri Xia Jiu Wen Kao 日下旧闻考(Ancient Stories Heard under the Throne) and Display Records.

\section{1)Ri Xia Jiu Wen Kao 日下旧闻考(Ancient Stories Heard under the Throne)}

Ri Xia Jiu Wen Kao 日下旧闻考(Ancient Stories Heard under the Throne) was published in the forty-eighth year of Qianlong.It described the architecture complexs in Qingyi Yuan in detail according to the architectural space orientation and poems written by Emperor Qianlong.But there were also some problems in it,such as missing a few architectures and confusing names.

2) Display Records
In order to facilitate the management, supplement and replacement of the interior furnishing of imperial buildings, Imperial Household Department 内务府 (Neiwu fu) made display records registering the information on indoor decoration and furnishing once the decoration was completed. These records may be divided into two categories according to the way of information recording. One is to describe the distribution and quantity of various furnishing according to their spatial positions within a room. This kind of information integrates the furnishing with the room, providing a full picture of the interior space; the other is to register the quantities of furnishing only, with recording the types and numbers of furnishings as the purpose.

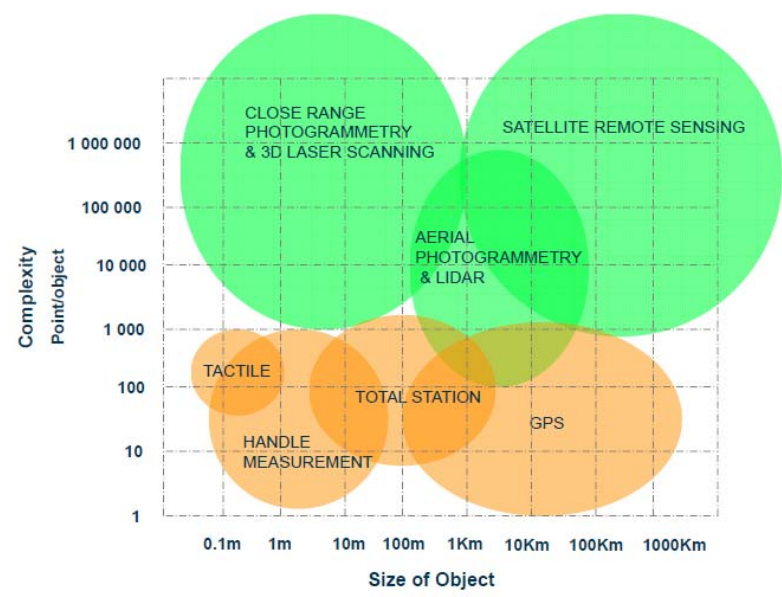

Fig. 1. Comparison of Survey Techniques of Heritage recording (From: Metric Survey for Heritage Documentation )

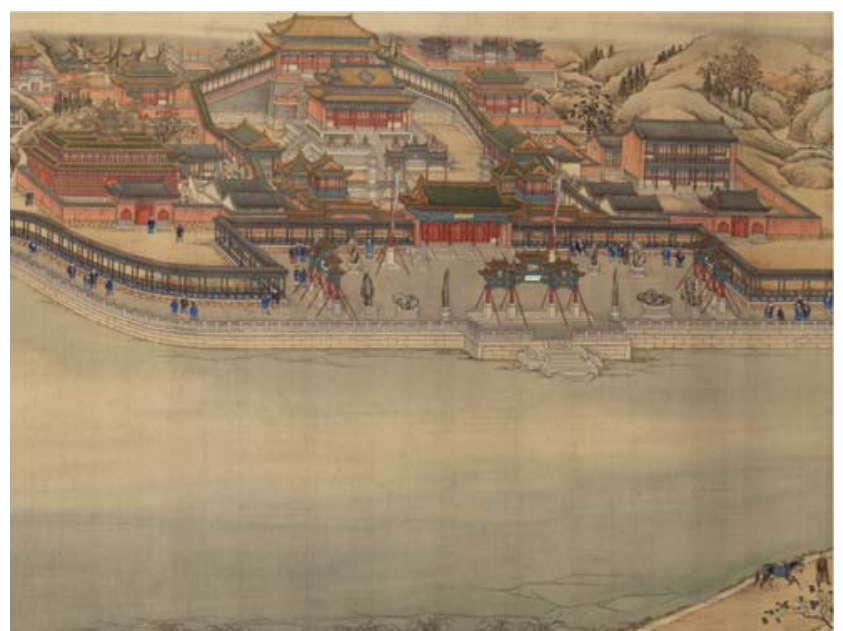

Fig.2. Da Bao En Yan Shou Temple 大报恩延寿寺 Wanshou qingdian tu (Painting of Birthday Celebration for the Chongqing Empress, 1760s )(Source: Palace Museum, Beijing)

\subsubsection{Survey drawings and documents}

During the restoration of the Summer Palace in 1886, architects made a detailed survey of the ruin of the Qingyi Yuan 清渏园 site, producing a large number of survey drawings and documentation for the purpose of restoration design. (Fig.3) 


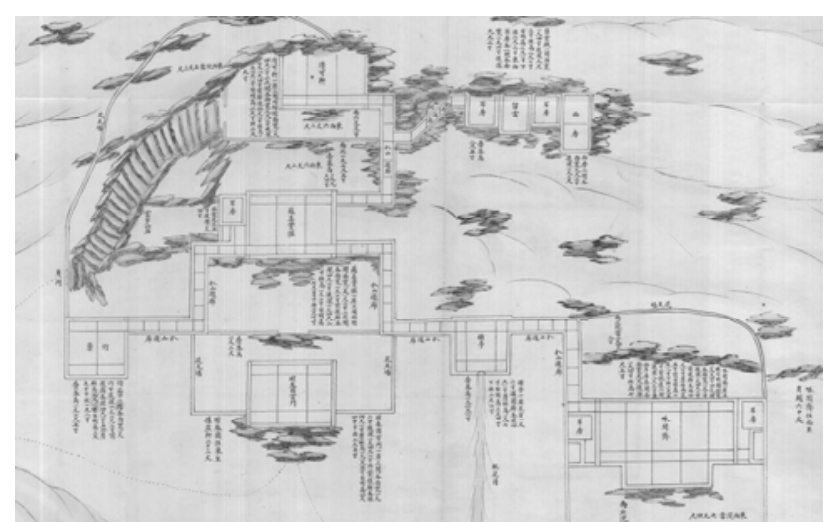

Fig.3. A survey drawing of Gaichun Yuan 赅春园 (Garden of Gathering the Spring) , 1887 (Source: National Library of China )

\subsection{Records from 1912 to 2004}

After the collapse of the Qing Dynasty, The Summer Palace was open to the public. For the purposes of management, restoration, research and display, managers and researchers have, from various perspectives, recorded information on the buildings in the Summer Palace using modern drawing standards. (Fig. 4, 5, 6)

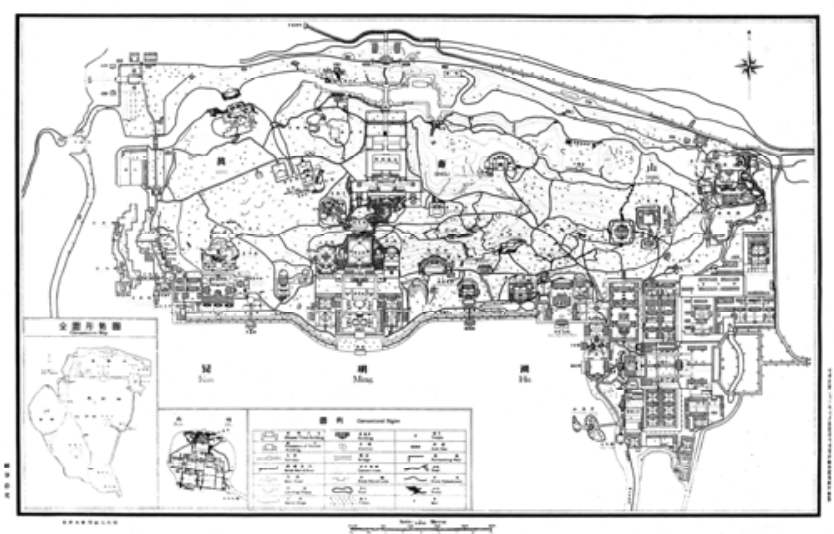

Fig. 4. A General Plan of the Summer Palace, 1934 (From: Administrative office of the Summer Palace)

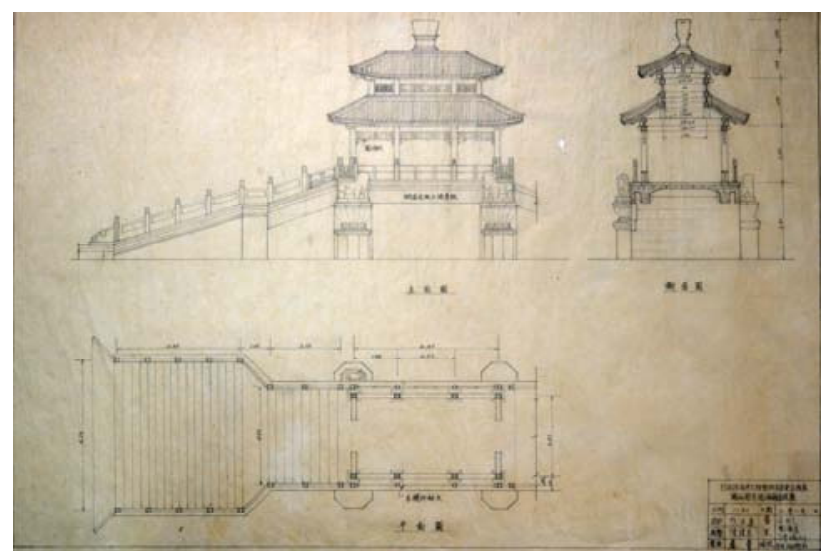

Fig. 5. A survey drawing of Xing Bridge 荇桥, 1948 (From: Chinese Academy of Cultural Heritage)

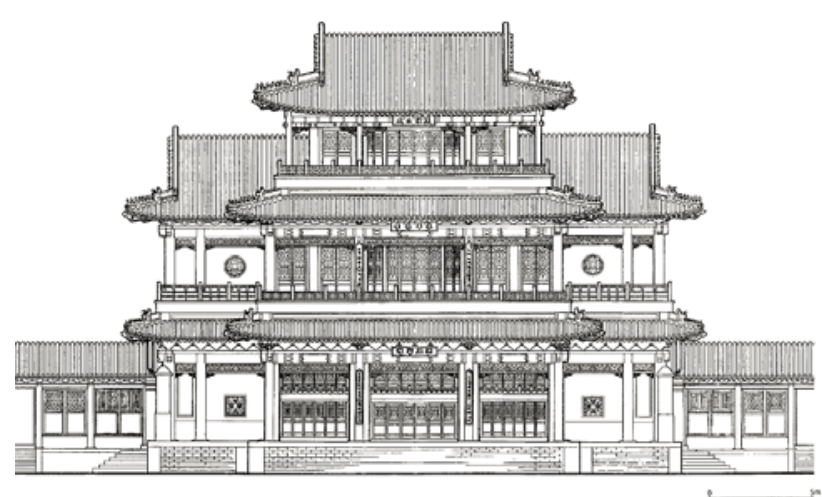

Fig. 6. A survey drawing of Da xilou 大戏楼 [The Opera Tower], 1950s (From: Tsinghua University, The Summer Palace, China Architecture \& Building Press, 2000)

\section{DIGITAL RECORDING PRACTICES AT THE SUMMER PALACE}

With the development of surveying technology such as 3D laser Scanning, GPS, Aerial Photogrammetry and BIM techniques, since 2005, the research team has collaborated closely with the Summer Palace in using digital technologies in information recording, thus opening the digital era of the Summer Palace information recording. These digital record practices helped the Summer Palace archives construction, aided in conservation planning and conservation implementation, and promoted thematic research like the Yangshi Lei architectural design drawings.

In the digital record practice of Summer Palace, we were always concerned about the purpose of recording and the demand of research and protection. Then select the most reasonable way to combinat the technologies, measure and record the architectural heritage reasonably. The Summer Palace architectural information records can be divided into the following four categories according to the demand.

\subsection{Architectural Archives Construction}

Survey drawing is an important content of architectural information archives. Design is a forward engineering, surveying is a reversed engineering. Reversed engineering has many unknown factors. The unknown factor of Surveying is that there are many hidden areas, and we can not obtain structural information in normal condition. In addition, the objects of surveying are generally antique, most of them have the problems of overall deformation, part modification and so on. This also brings trouble to surveying and mapping drawings. In view of this situation, we can divide the surveying work into typical surveying (ideal state surveying) and present situation surveying according to the different ways. The former chooses the typical section with better preservation and smaller deformation to measure according to the subjective judgment,and draws the ideal survey drawings. The latter measures the width, main component and section of the architecture entirely, and draws the real state at the moment.

We find in surveying practice that the 3D scanner have obvious advantages in the acquisition of whole spatial relations of architectures. But for the component level, such as sizes of beam, Fang, purlin section, Dougong, door and window, the error is far greater than the manual measurement. It can not achieve the nominal accuracy of the instrument. 
In additional, buildings are not a scientific instrument of precision. Fine interior furnishing allows inaccuracy of millimetres. In the case of using a 3D scanner to scan two samesized components (one with smooth surface, the other rough), the numerical difference of the results is about 1-2 $\mathrm{mm}$. Using the same scanner to scan the same component at different angles, the numerical difference is about $1-2 \mathrm{~mm}$ too. The same 3D laser scanner has high precision with a large-scale component and low precision with a small-scale component.

Therefore, the method of measurement is combining manual measurement with 3D scanning. Manual measurement is used to measure the size of main component section, and to identify the structural relations between the components. $3 \mathrm{D}$ scanning is used to control the whole spatial relations and that between the components. The typical drawings are drawn by typical data obtained by hand and 3D scanning. The present situation drawings is based on slice projection of 3D point cloud in corresponding position ,and combine manual measurement to describe the current situation.

The data of the hidden parts usually need to be measured by hand in the repair project,and be added into typical or present situation drawings. (Fig. 7, 8, 9)

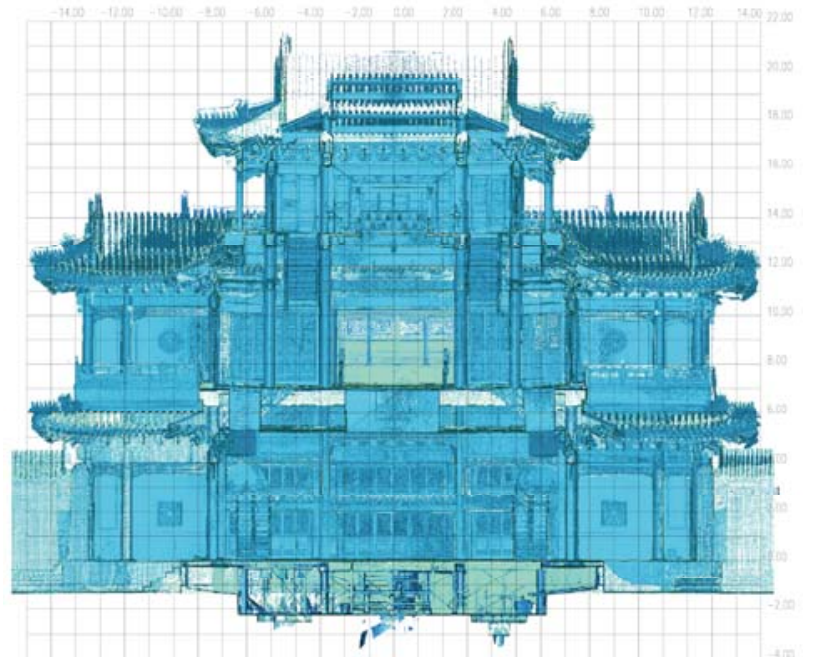

Fig.7. Piont cloud section of Daxi Lou

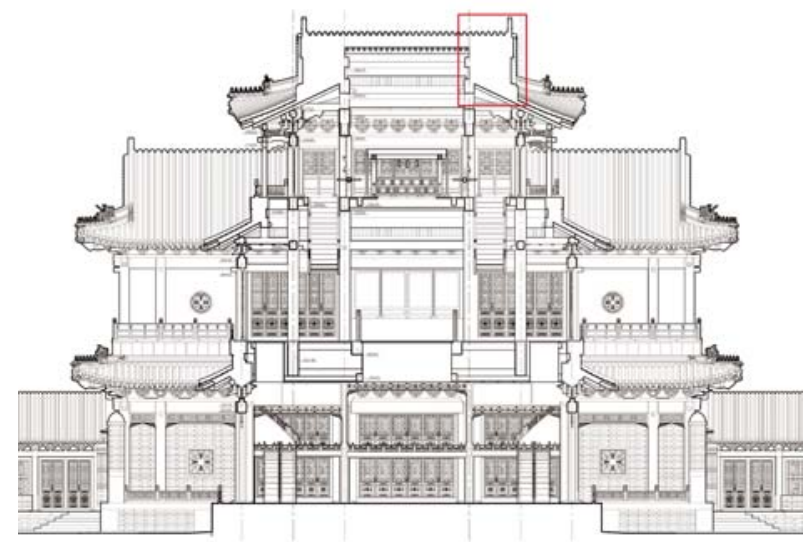

Fig.8. The section without hidden Parts of Daxi Lou

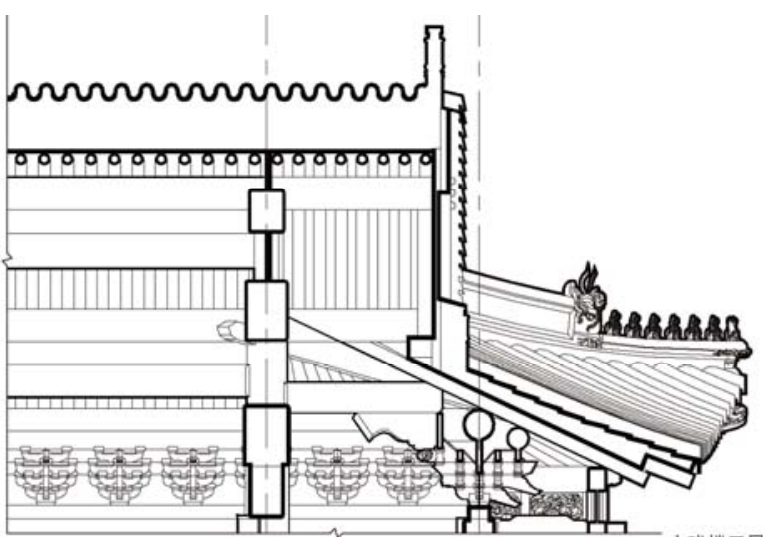

Fig.9. Add the hidden Parts of Daxi Lou's section during conservation project

\subsection{Supplementary Conservation}

Surveying is the primary work of architectural heritage protection, survey drawings are the base maps of design work. When we carry out a conservation project,if we aready have survey drawings, the investigation and design process can be sped up.In the investigation stage, based on the existing survey drawings, we can record the construction changes, deformation, damage and other issues emphatically, and then put forward the targeted protection program, These can be changed and marked on the basis of the survey drawings. In the past, this work mainly depends on $2 \mathrm{D}$ drawings and text. In the renovation of Deheyuan in the Summer Palace, we tried to build model by using BIM Technology. The information such as component age, material and damage condition was implanted into the model to realize visible display and management of architectural history information, physical information and spatial information.At the same time, we made a preliminary attempt to establish the Deheyuan information management platform based on GIS and BIM.It laid the foundation of the whole life-cycle management of the Deheyuan architectural complex.

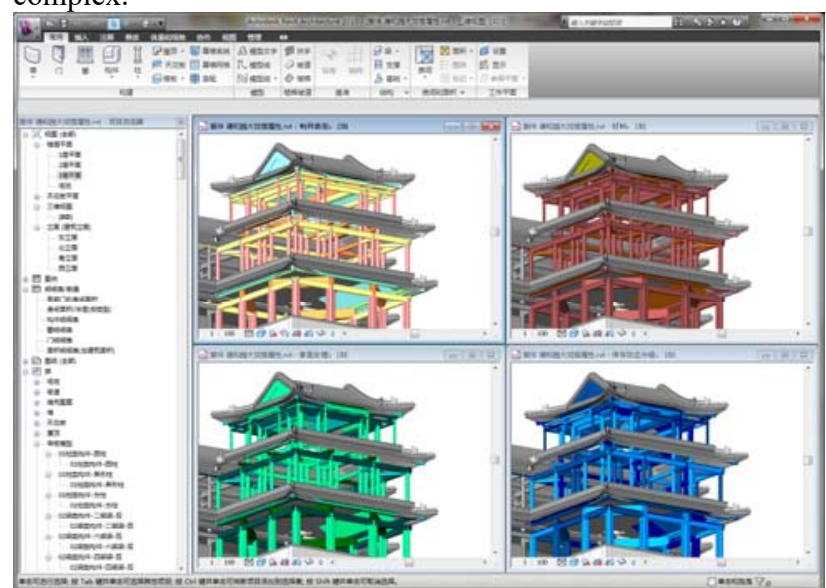

Fig.10. The Build Information Model (BIM) of Opera Tower [大戏楼], 2014

\subsection{Heritage display}

Architectural drawing is an important way to show the beauty of architecture.In order to show the"buildings wrap mountain" design intention of the front mountain in the Summer Palace, we control the front mountain buildings by GPS height and horizontal position. We piece together the elevation of the architectures on the front mountain and show the overall and 
uniform color through computer rendering. It shows the royal style and the"buildings wrap mountain" design intention well. (Fig. 11,12)For the elevation display of single building, we try to get orthophoto by 3D scanning, then carry on real texture mapping in Geomagic software. Show the public orthographic projection with the true colors, which is hard to see in reality. (Fig. 13)

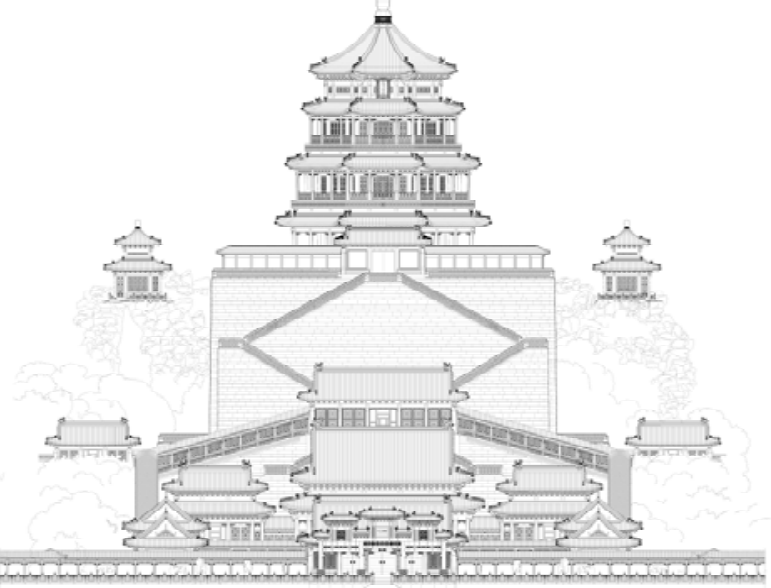

Fig.11. An elevation of the Paiyun Hall 排云殿 Group , 2006

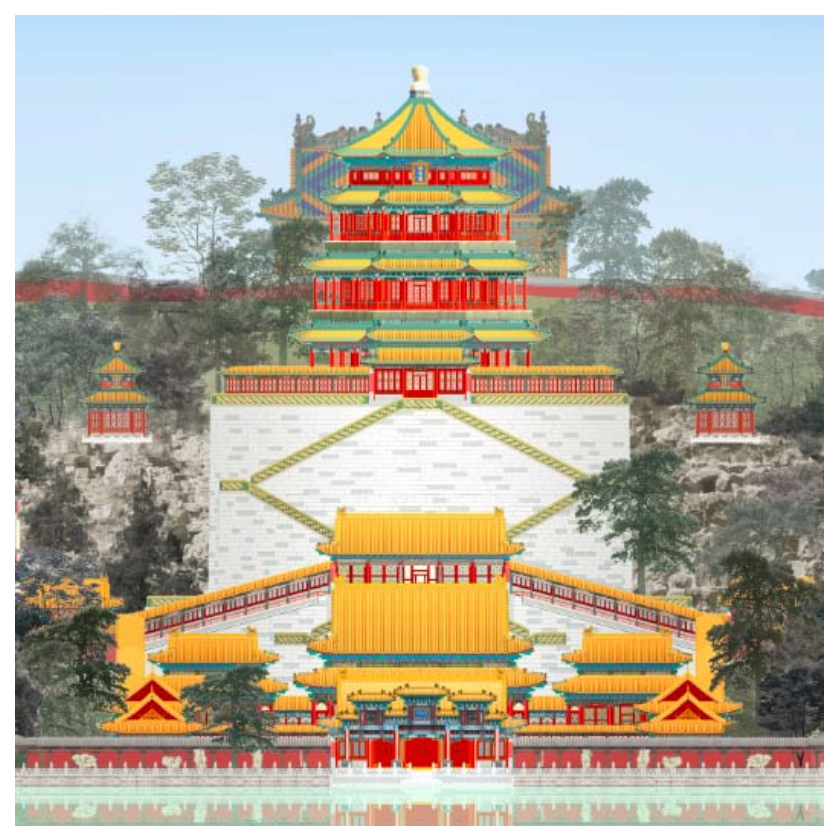

Fig.12. A coloured elevation of the Paiyun Hall 排云殿 Group, 2007

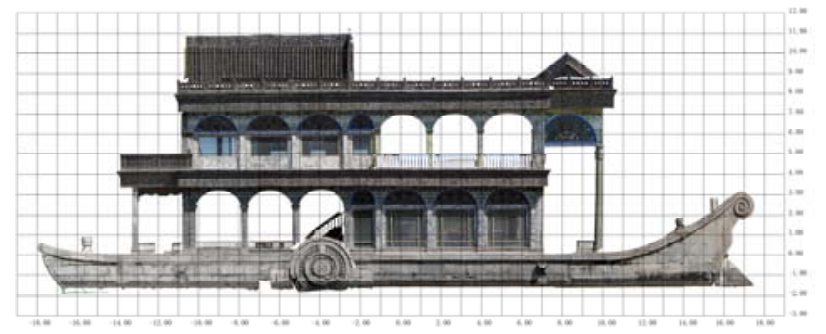

Fig.13. The Orthophoto of Stone Boat [石舫] , 2012

3.4 Thematic research

The participants of Summer Palace large-scale surveying include teachers, undergraduates, postgraduates and doctors, they drawed a total of nearly 4000 drawings. Contrast these survey drawings, we will find the different quality of them.It depends on the level of subjective recognition of the draftman first, followed by the basic skills of drawing, and finally the technical means of measurement. This phenomenon is obvious in the surveying include monographic study.For example, in order to survey the Eighteen Arhats in the Garden of Gathering spring 赅春园,we scaned the remaining statues the with the help of 3D scanner, took pictures, then used AutoCAD to draw 2D line drawing.In the first round of drawing,because the statue is damaged very serious,we didn't know the theme of the arhats and couldn't feature out the characteristic. The results were not only inaccurate sitting postures, fingerprints, musical instruments and clothes, but also rigid lines.Then,through the special study of the Eighteen Arhats, we compared the related images, identified the remaining statues, summarized each characteristics, and selected the handwriting board to describe them. The result was much better than the first round. (Fig. 14)
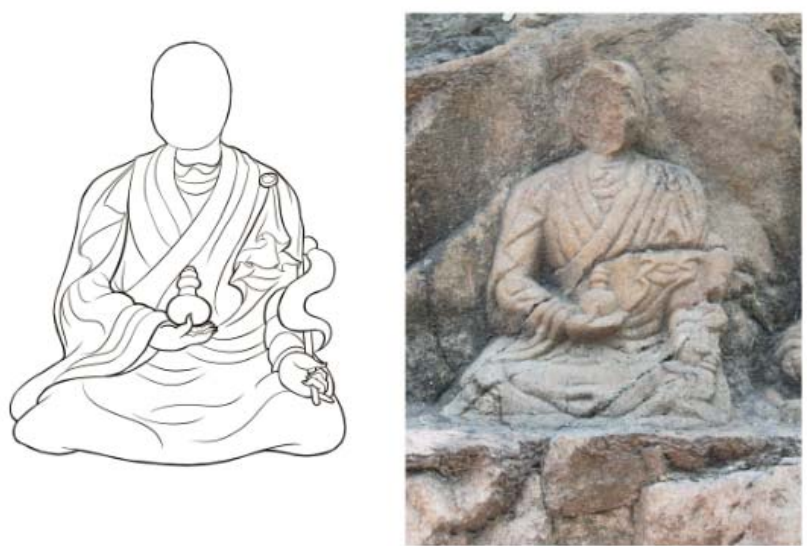

Fig.14. A Line drawing of a statue of Buddha in the Garden of Gathering spring 赅春园, 2009

\section{CONCLUSIONS}

\subsection{Cognition is more important than technology}

Collecting and recording architectural heritage information is based on the understanding of the value and nature of the heritage. Understanding is the purpose while information collection and recording are the means of heritage conservation.

\subsection{Demand determines technology}

Collecting and recording architectural heritage information serve heritage research, conservation, management and display. Different needs determine the different technical means that we use.

\subsection{The scale determines the accuracy}

In architectural heritage information recording, highest accuracy is not the golden criterion; accuracy at an appropriate level is. There is a deviation between the nominal accuracy of instrument and the accuracy in actual measurement.

\section{REFERENCES}

Bai Chengjun, Wu Cong, Zhang Long, 2013. Application of the Whole Series of 3D Laser Scanning Technology to Cultural 
relics and Archaeological Surveying. Journal of Tianjin University (Social Sciences), Vol.15, No.5 .436-439.

Chung, Anita.2004. Drawing boundaries: architectural images in Qing China. Honolulu : University of Hawaii Press.

English Heritage, 2006.Understanding Historic Buildings: A guide to good recording practice. Edited by John King and brought to press by Rachel Howard.

ICOMOS, 1990. Guide to Recording Historic Buildings, Photoset by Latimer Trend \& Company Ltd, Plymouth. Cambridge University Press.

John A. Burns and the staff of the Historic American Buildings Survey, Historic American Engineering Record, and Historic American Landscapes Survey, National Park Service, U.S. Department of the Interior,2004.Recording historic structures. Hoboken, N.J. : John Wiley \& Sons.

Tsinghua University, 2000. The Summer Palace. China Architecture \& Building Press.

Zhang Long, Xu Ruomu, Gu Yuan.2016.Research on the Cliffside Carving of the Eighteen Arhats of the Garden Gathering Spring[赅春园] in the Summer Palace. Culture Relics, (10) : 80-91 